\title{
Genetic diversity of Streptococcus suis isolates as determined by comparative genome hybridization
}

\author{
Astrid de Greeff ${ }^{*}$, Henk J Wisselink ${ }^{1}$, Freddy M de Bree ${ }^{1}$, Constance Schultsz ${ }^{2,3}$, Christoph G Baums ${ }^{4}$, \\ Hoa Ngo Thi ${ }^{3}$, Norbert Stockhofe-Zurwieden ${ }^{1}$ and Hilde E Smith ${ }^{1}$
}

\begin{abstract}
Background: Streptococcus suis is a zoonotic pathogen that causes infections in young piglets. S. suis is a heterogeneous species. Thirty-three different capsular serotypes have been described, that differ in virulence between as well as within serotypes.

Results: In this study, the correlation between gene content, serotype, phenotype and virulence among 55 S. suis strains was studied using Comparative Genome Hybridization (CGH). Clustering of CGH data divided S. suis isolates into two clusters, A and B. Cluster A isolates could be discriminated from cluster B isolates based on the protein expression of extracellular factor (EF). Cluster A contained serotype 1 and 2 isolates that were correlated with virulence. Cluster B mainly contained serotype 7 and 9 isolates. Genetic similarity was observed between serotype 7 and serotype 2 isolates that do not express muramidase released protein (MRP) and EF (MRP'EF-), suggesting these isolates originated from a common founder. Profiles of 25 putative virulence-associated genes of $S$. suis were determined among the 55 isolates. Presence of all 25 genes was shown for cluster A isolates, whereas cluster B isolates lacked one or more putative virulence genes. Divergence of $S$. suis isolates was further studied based on the presence of 39 regions of difference. Conservation of genes was evaluated by the definition of a core genome that contained $78 \%$ of all ORFs in P1/7.
\end{abstract}

Conclusions: In conclusion, we show that CGH is a valuable method to study distribution of genes or gene clusters among isolates in detail, yielding information on genetic similarity, and virulence traits of $\mathrm{S}$. suis isolates.

\section{Background}

Streptococcus suis forms a problem in the swine industry. Clinically healthy sows carry S. suis in their nasal cavities and on their tonsils, and transmit the bacteria to their piglets [1], that develop a variety of infections, such as septicaemia, meningitis, polyarthritis, and endocarditis, and often do not survive [2]. S. suis occasionally causes meningitis, arthritis or endocarditis in humans. However, recently several large human outbreaks of $S$. suis have been described in China [3,4], and Thailand [5], whilst $S$. suis meningitis has become endemic in Vietnam $[6,7]$, suggesting that isolates that are more virulent to humans have emerged.

\footnotetext{
* Correspondence: astrid.degreeff@wur.nl

'Infection Biology, Central Veterinary Institute of Wageningen UR (University \& Research Centre), Edelhertweg 15, Lelystad, 8219 PH, The Netherlands Full list of author information is available at the end of the article
}

The $S$. suis population is very heterogeneous as different serotypes, phenotypes, and genotypes are found. To date 33 capsular serotypes have been described for $S$. suis $[2,8]$ of which serotypes $1,2,7,9$, and 14 are most frequently isolated from diseased pigs in Europe [9]. In Northern America, besides these serotypes, serotypes 3 and 8 are frequently isolated from diseased animals $[10,11]$. On European farms, it was shown that up to $81 \%$ of healthy animals carried one or more serotypes simultaneously and different genotypes of the same serotype could be isolated at one timepoint from the same animal [12]. Different phenotypes of serotype 2 were described that differ in their virulence; strains can be differentiated by protein expression of virulence markers muramidase released protein (MRP), extracellular factor (EF) and suilysin (SLY) $[13,14]$. Besides variation in protein expression observed among S. suis strains, large

\section{Biomed Central}


heterogeneity also exists in gene composition [10,15-17]. Recently, the genome sequence of $S$. suis serotype 2 strain P1/7 became available [7] enabling whole genome typing techniques for $S$. suis. In the present study, we performed oligonucleotide-based comparative genome hybridization $(\mathrm{CGH})$ using the genome sequence of strain P1/7 to evaluate gene conservation and diversity among S. suis strains. Fifty-five well characterized S. suis strains of various serotypes were analyzed in this CGH study. Results from CGH were clustered, and correlated with MLST data, serotyping results, and virulence of strains. We showed that groups of S. suis isolates can be identified by their own unique profile of putative virulence genes and regions of difference. Besides, a core genome for $S$. suis was defined.

\section{Methods}

\section{Bacterial strains and growth conditions}

Bacterial isolates are described in Table 1. S. suis strains were grown on Columbia agar blood base plates (Oxoid Ltd., London, United Kingdom) containing 6\% (vol/vol) horse blood. Cultures were grown in Todd-Hewitt broth (Oxoid). Escherichia coli was grown in Luria Broth (Oxoid) and plated on Luria Broth Agar (Oxoid). S. suis isolates used in this study were serotyped using the slide-agglutination test [18] before they were used in the study (Table 1). Expression of three virulence markers, MRP, EF, and SLY $[19,20]$ was confirmed for all isolates by Western blot analysis [9] using monoclonal antibodies against MRP, EF [21], or SLY [22] (Table 1).

\section{Experimental infection in pigs}

All animal experiments were approved by the ethical committee of the Central Veterinary Institute of Wageningen UR in accordance with the Dutch law on animal experiments.

In this study virulence of $S$. suis isolates was strictly defined by the outcome of experimental infections. To study virulence of $S$. suis serotype 1 and 9 isolates, three successive experiments were performed in pigs. Previous to infection all piglets were tested negative for $S$. suis carriership. In all experiments pigs were allotted to three or four groups each consisting of four or five pigs (Table 2). In the first two experiments seventeen caesarian-derived germfree piglets were housed in stainless steel incubators as described before [21]. Each piglet was infected at the age of 5 days with Bordetella bronchiseptica $\left(3 \times 10^{7} \mathrm{CFU}\right.$, intranasally) to predispose animals for subsequent $S$. suis infection. Two days later animals were infected intranasally with exponentially growing $S$. suis strains $\left(1 \times 10^{6} \mathrm{CFU}\right.$ aerosol $)$.

In the third experiment, specific pathogen free (SPF) piglets with the age of 6 weeks were infected intranasally with $S$. suis serotype 9 isolates $\left(1 \times 10^{9} \mathrm{CFU}\right)$ without prior predisposition to B. bronchiseptica. Piglets were kept in sternal position and forced to inhale an aerosol produced by an airbrush (Badger, Franklin Park, USA) after anaesthesia with $50 \% \mathrm{O}_{2} / 50 \% \mathrm{~N}_{2} \mathrm{O} / 3 \%$ halothane.

In all experiments, piglets were followed clinically with special regard to signs of meningitis and arthritis. Swabs for bacteriological examination were taken daily from the oropharynx and faeces. Pigs were killed either moribund or 18 days post infection at the end of the observation period by intravenous injection of pentobarbiturate followed by exsanguination and necropsy. Tissue specimens from the central nervous system (CNS), serosae, and joints were examined bacteriologically and histologically $[21,23]$.

\section{Multi Locus Sequence Typing (MLST)}

MLST was performed as described by King et al. [24]. Alternative primers for mutS were used as described previously by Rehm et al. [25]. Chromosomal DNA was isolated from stationary growing bacteria as described previously [26]. PCR reactions were performed using Taq PCR Core kit (QIAgen, Hilden, Germany) according to the manufacturer's instructions, using $5 \mu \mathrm{l}$ of diluted (1:100) chromosomal DNA as template, containing at least $350 \mathrm{ng}$ of DNA. PCR products were visually inspected on $1 \%$ agarose gels containing ethidium bromide, and subsequently purified and sequenced by Macrogen (Macrogen, Seoul, Korea). Sequence data were analyzed using Lasergene software (DNAstar, Madison, USA). MLST alleles and resulting STs were assigned using the database on http://ssuis.mlst.net/. New alleles and STs were assigned by the curator of the database. Analysis of ST complexes was performed with eBURST http://www.mlst.net[27].

\section{S. suis oligoarray}

A S. suis oligoarray $(8 \times 15 \mathrm{~K})$ containing in situ synthesized 60-mers was produced by Agilent Technologies (Santa Clara, USA), according to a custom probe design based on the genome sequence of S. suis P1/7 [7]. A total of 7651 unique 60 -mers having a theoretical melting temperature of approximately $81^{\circ} \mathrm{C}$ and representing 1960 ORFs were selected as described by Saulnier et al. [28]. Genes were represented by 4 (91\%), 3 (4\%), 2 (2\%), or 1 probe $(3 \%)$. A total of 25 putative genes were not represented on the array because no unique probe satisfying the selection criteria could be selected.

\section{Comparative genome hybridization (CGH)}

Chromosomal DNA $(50 \mu \mathrm{g})$ was sheared in $1 \mathrm{ml}$ shearing buffer (TE/10\% glycerol), using Nebulizers (Invitrogen, Carlsbad, USA) under 1.7 bar air pressure for 3 minutes to yield fragments between 500 and 1500 bp. DNA was ethanol precipitated, taken up in water and $10 \mu \mathrm{g}$ of DNA was 
Table 1 Characteristics of bacterial strains used in this study

\begin{tabular}{|c|c|c|c|c|c|c|c|c|}
\hline Strain & Serotype & Virulence* $^{*}$ & ST & MRP $^{\#}$ & $\mathrm{EF}^{\#}$ & $\mathrm{SLY}^{\#}$ & Clinical source & Reference/source \\
\hline 6388 & 1 & $\mathrm{HV}$ & 1 & $S$ & + & + & Organs & Laboratory collection [32] \\
\hline 6112 & 1 & $\mathrm{HV}$ & 1 & S & + & + & Organs & Laboratory collection [32] \\
\hline $\mathrm{NCTC} 10273^{\mathrm{R} 1}$ & 1 & V & 13 & - & - & + & Unknown & Laboratory collection [32] \\
\hline $\mathrm{C} 160$ & 1 & ND & 1 & + & + & + & Brain/septicemia & Laboratory collection [9] \\
\hline C187 & 1 & ND & 132 & + & + & + & Tonsil/septicemia & Laboratory collection [9] \\
\hline OV585 & 1 & ND & 13 & - & - & + & Unknown & Veterinary Practice Diessen, The Netherlands \\
\hline 12 & 2 & $\mathrm{AV}$ & 19 & - & - & + & Tonsil & Laboratory collection [21] \\
\hline 16 & 2 & AV & 19 & - & - & $+/-$ & Tonsil & Laboratory collection [21] \\
\hline 25 & 2 & AV & 20 & - & - & + & Human & Laboratory collection [21] \\
\hline T15 & 2 & AV & 19 & - & - & + & Tonsil & Laboratory collection [23] \\
\hline 89-1591 & 2 & ND & 25 & - & - & - & Unknown & $\begin{array}{l}\text { Groupe de Recherché sur les Maladies Infectieuses du Porc, } \\
\text { Québec, Canada, [56] }\end{array}$ \\
\hline 3995 & 2 & ND & 1 & + & * & - & Unknown & Laboratory collection [16] \\
\hline 3988 & 2 & ND & 1 & + & * & - & Unknown & Laboratory collection \\
\hline 17 & 2 & WV & 8 & + & * & + & Tonsil & Laboratory collection \\
\hline $\mathrm{S} 735^{\mathrm{R} 2}$ & 2 & WV & 1 & + & * & + & Unknown & Laboratory collection CVI \\
\hline 1890 & 2 & ND & 133 & + & * & + & Unknown & Laboratory collection \\
\hline 3 & 2 & V & 1 & + & + & + & CNS & Laboratory collection [21] \\
\hline 10 & 2 & V & 1 & + & + & + & Tonsil & Laboratory collection [21] \\
\hline 22 & 2 & V & 1 & + & + & + & Human & Laboratory collection [21] \\
\hline D282 & 2 & V & 1 & + & + & + & CNS & Laboratory collection [21] \\
\hline 7696 & 2 & ND & 1 & + & + & + & Joint & $\begin{array}{l}\text { Groupe de Recherceh sur les Maladies Infectieuses du Porc, } \\
\text { Québec, Canada }\end{array}$ \\
\hline $\mathrm{P} 1 / 7$ & 2 & V & 1 & + & + & + & Unknown & Laboratory collection CVI \\
\hline BM190 & 2 & ND & 1 & + & * & + & $\begin{array}{l}\text { Human sepsis, } \\
\text { meningitis }\end{array}$ & Hospital for Tropical Diseases, Ho Chi Minh City, Vietnam \\
\hline BM191 & 2 & ND & 1 & + & * & + & Human meningitis & Hospital for Tropical Diseases, Ho Chi Minh City, Vietnam \\
\hline BM334 & 2 & ND & 1 & - & + & + & Human meningitis & Hospital for Tropical Diseases, Ho Chi Minh City, Vietnam \\
\hline BM407 & 2 & ND & 1 & - & * & + & Human meningitis & Hospital for Tropical Diseases, Ho Chi Minh City, Vietnam \\
\hline FX59 & 2 & ND & 1 & - & + & + & tonsil & Hospital for Tropical Diseases, Ho Chi Minh City, Vietnam \\
\hline FX125 & 2 & ND & 28 & + & - & - & tonsil & Hospital for Tropical Diseases, Ho Chi Minh City, Vietnam \\
\hline $95-8242$ & 2 & ND & 1 & + & + & + & Unknown & $\begin{array}{l}\text { Groupe de Recherceh sur les Maladies Infectieuses du Porc, } \\
\text { Québec, Canada }\end{array}$ \\
\hline 89-999 & 2 & ND & 25 & - & - & - & Unknown & $\begin{array}{l}\text { Groupe de Recherceh sur les Maladies Infectieuses du Porc, } \\
\text { Québec, Canada, [56] }\end{array}$ \\
\hline $\mathrm{R} 75 / \mathrm{S} 2$ & 2 & ND & 1 & + & + & + & Unknown & $\begin{array}{l}\text { Groupe de Recherceh sur les Maladies Infectieuses du Porc, } \\
\text { Québec, Canada, [56] }\end{array}$ \\
\hline $98 \mathrm{HAH} 12$ & 2 & ND & 7 & + & + & + & Human TSLS & $\begin{array}{l}\text { [41]Hua Dong Research Institute for Medicine of Nanjing } \\
\text { Command, Nanjing, China [41] }\end{array}$ \\
\hline 05ZYH33 & 2 & ND & 7 & + & + & + & Human TSLS & $\begin{array}{l}\text { [41]Hua Dong Research Institute for Medicine of Nanjing } \\
\text { Command, Nanjing, China [41] }\end{array}$ \\
\hline OV233 & 2 & ND & 1 & + & + & + & Unknown & Veterinary Practice Diessen, The Netherlands \\
\hline OV349 & 2 & ND & 1 & + & + & + & Unknown & Veterinary Practice Diessen, The Netherlands \\
\hline OV625 & 2 & ND & 1 & + & + & + & Unknown & Veterinary Practice Diessen, The Netherlands \\
\hline OV209 & 4 & ND & 17 & $\mathrm{~s}$ & - & - & Unknown & Veterinary Practice Diessen, The Netherlands \\
\hline 7711 & 7 & ND & 29 & - & - & - & CNS & Laboratory collection [9] \\
\hline 7917 & 7 & ND & 29 & - & - & & CNS & Laboratory collection [9] \\
\hline 8039 & 7 & ND & 135 & - & - & - & CNS & Laboratory collection [9] \\
\hline C126 & 7 & ND & 1 & - & - & - & Joint & Laboratory collection [9] \\
\hline 15009 & 7 & ND & 89 & - & - & - & Unknown & Laboratory collection [9] \\
\hline A496/98 & 7 & ND & 29 & - & - & - & Lung, pneumonia & $\begin{array}{l}\text { Stiftung Tierärtzliche Hochschule Hannover, Hannover, Germany } \\
\text { [25] }\end{array}$ \\
\hline Sw123/B2452 & 7 & ND & 29 & - & - & - & Lung, pneumonia & $\begin{array}{l}\text { Stiftung Tierärtzliche Hochschule Hannover, Hannover, Germany } \\
\text { [25] }\end{array}$ \\
\hline
\end{tabular}


Table 1 Characteristics of bacterial strains used in this study (Continued)

\begin{tabular}{|c|c|c|c|c|c|c|c|c|}
\hline $8074^{R 7}$ & 7 & ND & 25 & - & & - & Unknown & Laboratory collection CVI \\
\hline 7997 & 9 & AV & 16 & * & - & + & Organs & Laboratory collection [9] \\
\hline 8067 & 9 & AV & 136 & - & - & + & Unknown & Laboratory collection [9] \\
\hline 8017 & 9 & $\mathrm{AV}$ & 136 & - & - & + & CNS & Laboratory collection [9] \\
\hline 7709 & 9 & ND & 16 & * & - & + & Bacteraemia & Laboratory collection [9] \\
\hline C132 & 9 & ND & 16 & * & - & + & Brain/septicemia & Laboratory collection [9] \\
\hline 5973 & 9 & AV & 137 & * & - & - & CNS & Laboratory collection [9] \\
\hline $22083^{R 9}$ & 9 & ND & 82 & * & - & - & Unknown & Laboratory collection CVI \\
\hline 7998 & 9 & ND & 16 & + & - & + & Joint & Laboratory collection [9] \\
\hline 8186 & 9 & ND & 138 & * & - & - & Tonsil & Laboratory collection [9] \\
\hline OV640 & UT & ND & 139 & * & - & - & Unknown & Veterinary Practice Diessen, The Netherlands \\
\hline 2840 & PA & ND & 134 & - & * & + & Unknown & Laboratory collection \\
\hline $\begin{array}{l}\text { Escherichia } \\
\text { coli TG1 }\end{array}$ & NA & NA & NA & NA & NA & NA & NA & Laboratory collection \\
\hline
\end{tabular}

${ }^{\mathrm{Rx}}$ reference strain of serotype $\mathrm{x}$; UT untypable; PA, poly-agglutination; NA, not applicable; HV, highly virulent; V, virulent; WV, weakly virulent; AV, avirulent; ND, not determined; MRP, muramidase released protein; EF, extracellular factor; SLY, suilysin; +, protein expressed; -, protein not expressed; *, higher MW protein expressed; s, smaller MW protein expressed; +/-, protein weakly expressed; CNS, central nervous system; TSLS, toxic shock-like syndrome

* virulence as determined in an experimental infection in pigs

\# phenotype, protein expression

column purified using Illustra Cyscribe GFX purification kit (GE Healthcare, Uppsala, Sweden) according to instructions of the manufacturer. Differential DNA presence was determined by two-colour fluorescent hybridizations of the corresponding genomic DNAs on the $8 \times$ $15 \mathrm{k}$ S. suis oligo array. Genomic DNA of each strain was cohybridized once with the reference strain P1/7, that was always labeled with Cy3. The test strain was consequently labeled with Cy5. Labeling of DNA $(2,5 \mu \mathrm{g})$ was done using the Bioprime Array CGH Genomic Labeling System (Invitrogen) with slight modifications as described by Molenaar et al., 2005 [29]. Labeling efficiency was measured using the Nanodrop (ThermoScientific, Wilmington, USA). Constant amounts of label ( 25 pmol each) were hybridized to the oligoarray in hybridization buffer of the In situ hybridization kit Plus (Agilent Technologies) following instructions of the manufacturer. During hybridization, slides were incubated for $17 \mathrm{~h}$ at $65^{\circ} \mathrm{C}$ under rotation. Slides were washed for $10 \mathrm{~min}$ in $6 \times \mathrm{SSC} / 0.05 \%$ Triton$\mathrm{X} 102$ at room temperature, followed by $5 \mathrm{~min}$ in $0.1 \times$ $\mathrm{SSC} / 0.05 \%$ Triton-X102 at $4^{\circ} \mathrm{C}$. Slides were dried using pressured air and scanned in a GenePix 4200AL scanner (Molecular Devices, Sunnyvale, USA). Scans were analyzed using GenePix software (Molecular Devices). Local background values were subtracted from the intensity of each spot. Data were normalized using S-Lowess [30] at the webtool accessible from http://bioinformatics.biol.rug.nl/ websoftware/s-lowess. Normalized data were imported into Acuity software (Molecular Devices) for further analysis. Cut-off values for presence/absence of genes were empirically determined by comparing microarray results to classic hybridization results using about 100 radioactively labeled probes on spotted chromosomal DNA (data not shown). It was determined that a $\log$ ratio above -1.5 indicated the gene was present and very homologous to the gene in P1/7, whereas a log ratio above -4.5 indicated that the gene was present, but variation in nucleotide composition existed among isolates. A ratio between -1.5 and -3 indicated slight variation, whereas a ratio between -3 and -4.5 indicated large variation. A gene was designated "absent" from a genome when all probes for that gene had a normalized log ratio below -4.5 .

\section{Dendrograms}

CGH data was clustered using Acuity software to determine similarity of isolates tested in the CGH. Hierarchical clustering of isolates was done by clustering arrays based on ranked correlation coefficients (Spearman's rho), where linkage was determined using the average neighbours method. P-values were calculated by multiscale bootstrap resampling $(\mathrm{n}=10000)$ with the R package pvclust using the average agglomerative method and by the absolute correlative distance measure. The presence of putative virulence genes among isolates, as well as the presence of regions of difference among isolates, was visualized in dendrograms using BioNumerics (Applied Maths, Houston, USA) to study similarity among isolates. These data were analyzed using the Pearson product-moment correlation coefficient. Cluster analysis was done with the unweighted pair group method using arithmetic averages (UPGMA) with a $1 \%$ optimization for position tolerance.

\section{Microarray data}

All microarray data have been submitted MIAME complied to ArrayExpress under submission numbers 
Table 2 Virulence of Streptococcus suis serotype 1 and 9 strains determined in pigs

\begin{tabular}{|c|c|c|c|c|c|c|c|c|c|c|c|c|c|}
\hline $\begin{array}{l}\text { S. suis } \\
\text { strain }\end{array}$ & $\begin{array}{l}\text { Sero- } \\
\text { type }\end{array}$ & Dose & $\begin{array}{l}\text { No. of } \\
\text { pigs }\end{array}$ & $\begin{array}{c}\text { Mortality } \\
(\%)\end{array}$ & $\begin{array}{l}\text { Mean time until } \\
\text { death (days) }\end{array}$ & $\begin{array}{c}\text { Specific } \\
\text { Clinical } \\
\text { Signs }^{1}\end{array}$ & $\begin{array}{c}\text { Non- } \\
\text { Specific } \\
\text { Clinical } \\
\text { Signs }^{2}\end{array}$ & $\begin{array}{l}\text { Path. } \\
\text { CNS }\end{array}$ & $\begin{array}{l}\text { Bact. } \\
\text { CNS }\end{array}$ & $\begin{array}{l}\text { Path. } \\
\text { serosae }\end{array}$ & $\begin{array}{l}\text { Bact. } \\
\text { serosae }\end{array}$ & $\begin{array}{l}\text { Path. } \\
\text { joints }\end{array}$ & $\begin{array}{l}\text { Bact. } \\
\text { joints }\end{array}$ \\
\hline 6388 & 1 & $\begin{array}{l}10^{6} \\
\mathrm{CFU}^{\$}\end{array}$ & $5^{C D}$ & 100 & 2 & 17 & 37 & 4 & 4 & 4 & 4 & 2 & 4 \\
\hline 6112 & 1 & $\begin{array}{l}10^{6} \\
\text { CFU }^{\$}\end{array}$ & $4^{\mathrm{CD}}$ & 100 & 2 & 7 & 36 & 3 & 4 & 1 & 4 & 0 & 4 \\
\hline NCTC10273 & 1 & $\begin{array}{l}10^{6} \\
\mathrm{CFU}^{\$}\end{array}$ & $4^{\mathrm{CD}}$ & 100 & 9.8 & 6 & 21 & 1 & 2 & 1 & 2 & 4 & 4 \\
\hline 3 & 2 & $\begin{array}{l}10^{6} \\
\text { CFU }^{\$}\end{array}$ & $4^{C D}$ & 50 & 7 & 4 & 67 & 0 & 0 & 4 & 3 & 0 & 0 \\
\hline 3 & 2 & $\begin{array}{l}10^{6} \\
\text { CFU }^{\$}\end{array}$ & $4^{C D}$ & 50 & 7.5 & 25 & 87 & 3 & 3 & 3 & 1 & 2 & 3 \\
\hline 5973 & 9 & $\begin{array}{l}10^{6} \\
C F U^{\$}\end{array}$ & $5^{\mathrm{CD}}$ & 0 & NA & 0 & 0 & 0 & 0 & 2 & 1 & 0 & 0 \\
\hline $22083^{R 9}$ & 9 & $\begin{array}{l}10^{6} \\
\mathrm{CFU}^{\$}\end{array}$ & $4^{\mathrm{CD}}$ & 0 & NA & 0 & 0 & 0 & 0 & 0 & 0 & 0 & 1 \\
\hline $22083^{R 9}$ & 9 & $\begin{array}{l}10^{9} \\
\text { CFU }\end{array}$ & $4^{\text {SPF }}$ & 0 & NA & 13 & 0 & 1 & 0 & 0 & 0 & 0 & 1 \\
\hline 7997 & 9 & $\begin{array}{l}10^{9} \\
\text { CFU }\end{array}$ & $4^{\mathrm{SPF}}$ & 25 & 4 & 1 & 2 & 1 & 1 & 0 & 1 & 1 & 2 \\
\hline 8067 & 9 & $\begin{array}{l}10^{9} \\
\text { CFU }\end{array}$ & $4^{\mathrm{SPF}}$ & 0 & NA & 10 & 1 & 0 & 0 & 1 & 0 & 1 & 0 \\
\hline 28017 & 9 & $\begin{array}{l}10^{9} \\
\text { CFU }\end{array}$ & $4^{\mathrm{SPF}}$ & 25 & 1 & 1 & 0 & 1 & 1 & 2 & 0 & 1 & 2 \\
\hline
\end{tabular}

\$Animals were predisposed with a B. bronchiseptica infection 2 days before infection with S. suis; ${ }^{C D}$ caesarean-derived germfree piglets; ${ }^{\text {SPF }}$ specific pathogen free piglets; ${ }^{1}$ mean number of observations of nervous signs and lameness in one or more joints/total number of observations $\times 100 \%$; ${ }^{2}$ mean number of observations of inappetence and depression/total number of observations $\times 100 \%$; Path. Pathology: number of pigs with pathological abnormalities; Bact. Bacteriology: Number of piglets from which S. suis is reisolated; NA, animals survived until the end of the experiment; CNS Central nervous system.

E-MEXP-2531/E-MEXP-2533 http://www.ebi.ac.uk/ microarray-as/ae/.

\section{Results}

\section{Clustering of isolates as determined by $\mathrm{CGH}$}

$\mathrm{CGH}$ was used to study genomic diversity among S. suis isolates. S. suis isolates from different serotypes, isolated from different hosts, from different clinical sources, and from different geographical locations were included in the study (Table 1). The dendrogram depicting the $\mathrm{CGH}$ data (Figure 1) shows that isolates were divided into 2 clusters, $\mathrm{A}$ and $\mathrm{B}$, whereas the negative control $E$. coli strain was assigned to cluster $C$. This indicates that there are extensive genetic differences between S. suis isolates belonging to clusters A and B. Statistical analysis showed that subclustering of isolates in cluster B was highly significant (indicated in Figure 1), whereas subclustering of isolates in cluster A was less significant. This is probably due to high similarity among cluster A isolates. One statistical outlier was identified, isolate 6388 clustered with $E$. coli $(\mathrm{p}=0.6)$ in a separate cluster due to low microarray signals. This was only detected after multiple bootstrap resampling.

Cluster A exclusively contained serotype 1 and 2 isolates, except for one (isolate 2840), indicating that these serotypes are genetically very similar. Isolate 2840 was identified to be poly-agglutinable in a slide agglutination test, although CGH data showed this isolate contains cps genes of serotype 2 , suggesting the isolate belongs to serotype 2 but does not express (enough) capsule genes sufficiently to be detected in slide agglutination. All isolates in cluster A expressed either EF protein or the larger form $\mathrm{EF}^{*}$ protein [16], whereas none of the isolates clustered in group B expressed either of these proteins. MLST analysis showed that with the exception of serotype 2 isolate 1890, all isolates in cluster A belonged to clonal complex 1 (CC1) within which most isolates were found to represent sequence type 1 (ST1) whereas others represented single locus variants of ST1. Six subclusters (A1 - A6) were distinguished in cluster A. Cluster A1 contained $\mathrm{MRP}^{+} \mathrm{EF}^{+}$serotype 2 isolates from different geographical locations (Canada, Netherlands and China) that were isolated from humans and pigs, indicating the global spreading of these isolates. Cluster A2 exclusively contained serotype 2 isolates from Vietnam either obtained from human patients or from pigs [6], suggesting these Vietnamese isolates are highly similar to each other. Discrimination of isolates of the subclusters A1 A6 was based on sequence diversity between genes, rather than on differences in gene content. 


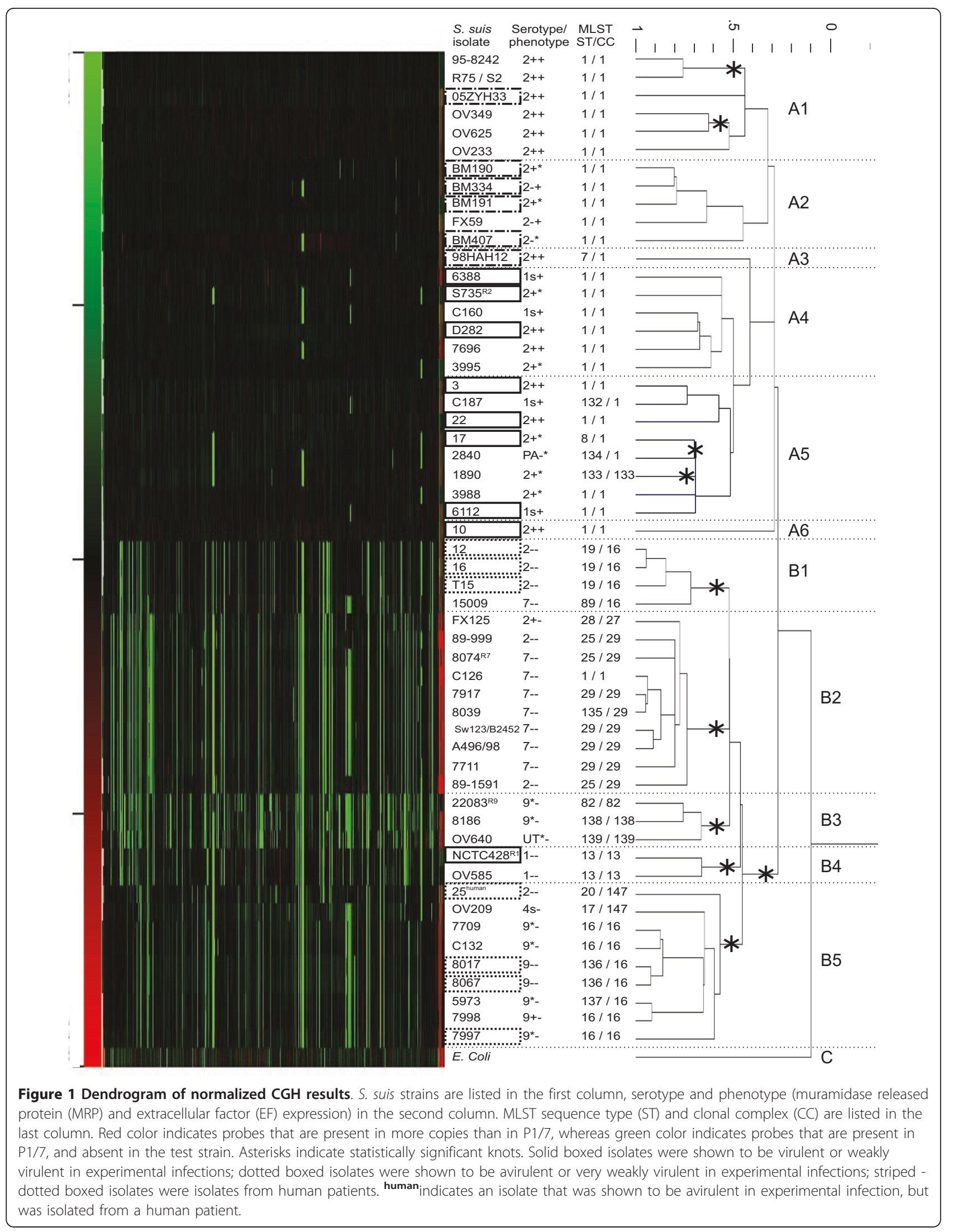


In contrast to cluster A, cluster B contained a more divergent, heterogeneous group of isolates. Cluster B contained all serotype 7 and 9 isolates included in this study as well as a number of less virulent serotype 1 and serotype 2 isolates that neither express MRP nor EF. Within cluster B five subclusters were distinguished (B1 - B5). Subclusters B1 and B2 contained all serotype 7 isolates, as well as a number of $\mathrm{MRP}^{-} \mathrm{EF}^{-}$serotype 2 isolates [21]. The high degree of similarity observed between $\mathrm{MRP}^{-} \mathrm{EF}^{-}$serotype 2 and serotype 7 isolates could suggest that the $\mathrm{MRP}^{-} \mathrm{EF}^{-}$serotype 2 isolates originated from serotype 7 isolates by an exchange of capsular genes. This idea is supported by MLST data which showed that most isolates within the clusters B1 and B2 share the same clonal complex (respectively 16 and 29) as well as by AFLP-data in which these isolates also clustered together (data not shown). Cluster B3 was a very heterogeneous group of isolates that seemed to contain isolates that were clustered based on lack of genetic similarity to each other and to other strains. Surprisingly, the reference strain of serotype $9\left(22083^{\mathrm{R} 9}\right)$ was assigned to cluster B3 as well, at large distance from other serotype 9 isolates in cluster B5. This clearly indicates that the reference strain does not represent the European serotype 9 isolates from the field used in this study. This was confirmed by MLST data, since this reference strain was assigned to ST82, an independent ST, outside a lineage. Cluster B4 contained two serotype 1 isolates among which the reference strain of serotype 1 (NCTC10273 $\left.{ }^{\mathrm{R} 1}\right)$, indicating extensive sequence differences between serotype 1 strains in cluster B4 and serotype 1 strains in cluster $A$. In contrast to the serotype 1 isolates present in cluster A, both isolates in cluster B4 were negative for expression of MRP and EF and belonged to $\mathrm{CC} 13$, whereas all serotype 1 isolates in cluster A belonged to $\mathrm{CC} 1$. Therefore, the reference strain for serotype 1 at best represents part of the serotype 1 population. Cluster B5 contained serotype 9 isolates belonging to $\mathrm{CC} 16$ as well as a serotype 2 isolate from a human patient and a serotype 4 isolate both belonging to CC147.

\section{Virulence of S. suis isolates of serotype 1 and 9}

To be able to study the correlation of gene content of isolates with virulence, we determined the virulence of serotype 1 and 9 isolates used in this study in experimental infections in pigs in comparison to the virulence of serotype 2 strain 3 [21]. The reference strains of serotype 1 and 9 were included in this experimental infection, as well as 2 - 3 field isolates of both serotypes. Table 2 shows that although serotype 1 reference strain NCTC10273 ${ }^{\mathrm{R} 1}$ showed less clinical signs than serotype 2 strain 3, mortality of serotype 1 reference strain was $100 \%$ whereas strain 2 showed only 50\% mortality. Four piglets infected with this serotype 1 strain showed pathological abnormalities in joints. Based on morbidity, mortality and pathological abnormalities in $>50 \%$ of piglets, isolate NCTC10273 ${ }^{\mathrm{R} 1}$ is considered virulent, like strain 3. Serotype 1 isolates 6112 and 6388 also showed a mortality rate of $100 \%$. The mean number of days until death of these animals was 2 days, whereas for piglets infected with the serotype 1 reference strain this was 9.8 days. Animals infected with strain 3 showed $50 \%$ mortality and a mean number of days until death of more than 7 days post-infection. Isolates 6112 and 6388 induced pathological abnormalities in CNS in 4 out of 5 piglets and 3 out of 5 piglets, respectively. Based on these observations, these serotype 1 isolates are considered more virulent than strain 3 and are therefore considered highly virulent. Serotype 9 isolates did not show any clinical symptoms after an intranasal infection with $10^{6}$ CFU (Table 2), whereas strain 3 showed $50 \%$ mortality and a mean number of days until death of 7.5. Even an infection dose of $10^{9} \mathrm{CFU}$ of serotype 9 only induced mild clinical signs, and sparse pathological findings. This led to the conclusion that the serotype 9 isolates tested in our experimental infection model should be considered avirulent, although they can induce mild clinical symptoms at a higher dose.

Virulence of isolates as determined in experimental infections in pigs was depicted in the dendrogram of $\mathrm{CGH}$ data (Figure 1). Except for the virulent reference strain of serotype 1 that was assigned to cluster B4, all avirulent isolates were assigned to cluster B, whereas all virulent, highly virulent and weakly virulent isolates were assigned to cluster A. MLST data confirmed these findings, since all isolates in cluster A, except for isolate 1890, belonged to MLST CC1 that was described to have a strong correlation with invasive diseases, like septicemia, meningitis and arthritis [24]. All Asian human isolates that were obtained from meningitis and sepsis patients were assigned to cluster A as well. The only Dutch human isolate from a meningitis patient (isolate 25) was shown to be avirulent in an experimental infection in piglets, and was assigned to cluster B, clearly indicating that this isolate is genetically distinct from the highly virulent Asian human isolates [3,4].

\section{Distribution of putative virulence related genes among $S$. suis serotype 2 isolates}

To correlate virulence of isolates with specific genes, we next studied the distribution of 25 genes encoding putative virulence proteins in serotype 2 isolates among isolates. Genes were selected that were described to be involved in pathogenesis or virulence of S. suis. Clustering of these results into a dendrogram assigned all isolates to 7 different virulence clusters (V1 - V7) (Figure 2 ). This clustering was very similar to the clustering 


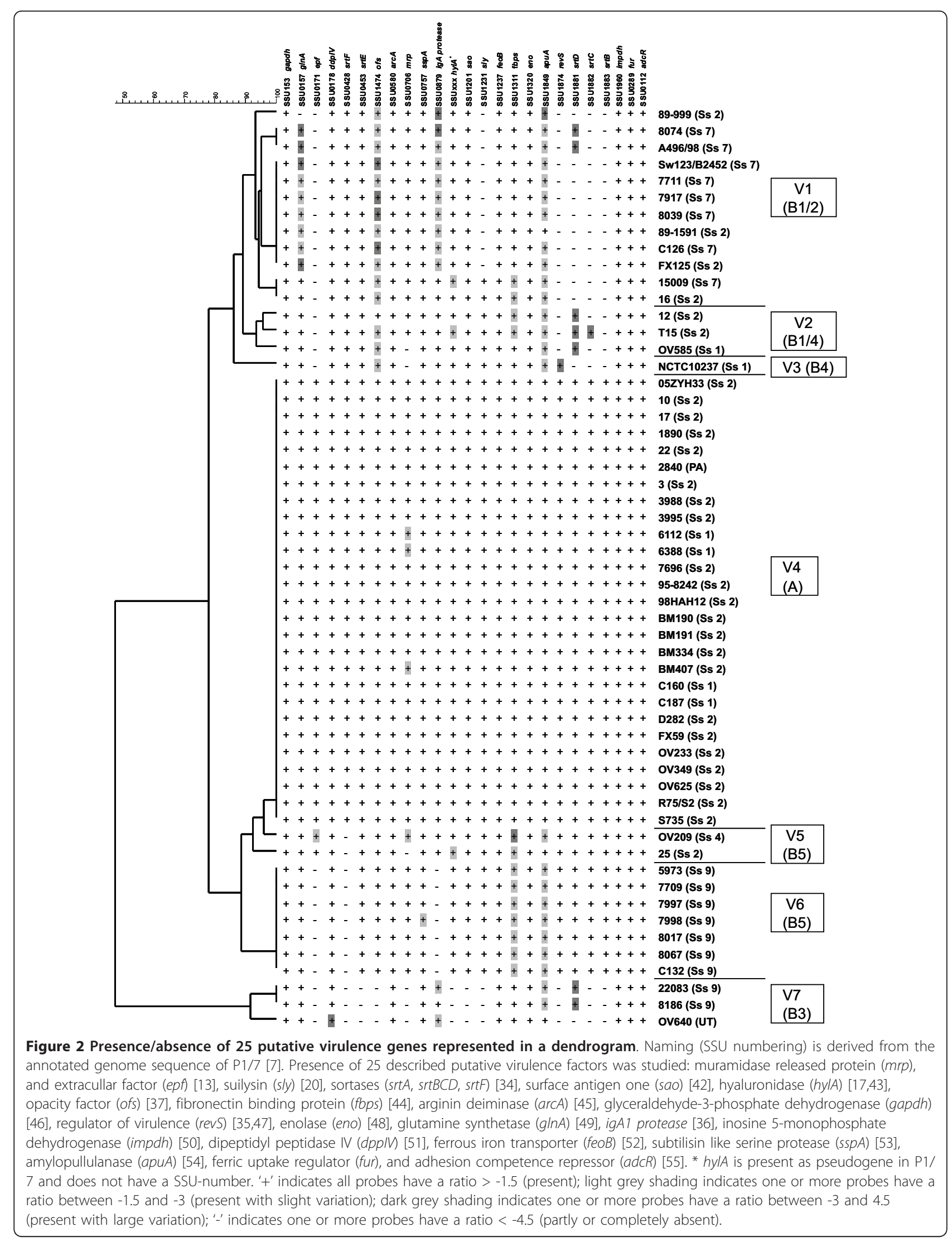


based on the CGH data, although some isolates were clustered with isolates that belonged to another CGH cluster. Isolates assigned to cluster V4 (corresponding to CGH cluster A) contained all selected putative virulence genes, whereas isolates assigned to clusters V1, V2, V3, V5, V6 and V7 (corresponding to CGH cluster B) lacked 1 to 12 of these genes. All cluster B isolates lacked either one or more sortase genes that are involved in assembly of pili [31]. Serotype 7 isolates all clustered to $\mathrm{V} 1$ together with $\mathrm{MRP}^{-} \mathrm{EF}^{-}$serotype 2 isolates. All V1 isolates lacked regulator of virulence revS, epf and $\operatorname{srtB}$ and $\operatorname{srt} C$, whereas they contained $\operatorname{srt} E$, $s r t F$ and two isolates contained $s r t D$, but with extensive sequence variation. Serotype 9 isolates fell apart in two different clusters, V6 and V7. Cluster V6 lacked IgA protease, $s r t F$, and epf, and showed minor sequence variation in apuA and fbps. V7 isolates lacked at least 11 putative virulence genes, among which all sortase genes. This indicated that V7 isolates are incapable of pilus formation, and are thereby likely to be less virulent. Taken together, our data suggests that differences in virulence exist within the serotype 9 population. Extensive sequence variation in a limited number of putative virulence genes ( $g \ln A$, ofs, IgA protease, apuA, fbps, srtD) was detected in isolates belonging to clusters V1, V2, V3, V5, V6 and V7, but not in V4 isolates (Figure 2). This suggests that V4 isolates are genetically more similar to each other and to P1/7, the array strain. V4 isolates exclusively express $\mathrm{EF}$, none of the isolates in clusters V1, V2, V3, V5, V6 express EF (Table 1). In this study we show that most isolates are unable to express the protein since they lacked the epf gene encoding EF. Two V5 isolates have a silent epf gene. Presence of $m r p$ and sly genes was less indicative for protein expression. Isolates 3995, 3988, OV209, 15009, and 5973 contained the suilysin gene, but did not express the protein under in vitro conditions (Table 1). Almost all isolates tested in this study contained the mrp gene, whereas less than half expressed the protein under in vitro conditions (Table 1 and Figure 2) [13].

\section{Regions of differences and core genome of $S$. suis}

To further explore genetic diversity between S. suis isolates, regions of difference (RDs) were identified, which were defined as at least three consecutive ORFs that were absent from at least one strain. Thirty-nine RDs that varied in size from $461 \mathrm{bp}$ to $27 \mathrm{kbp}$ were identified. The largest RD (27 kbp) contained cps genes encoding serotype specific polysaccharide capsule of P1/7 (serotype 2) (Table 3). Other RDs contained $A B C$ transporters, restriction modification systems, signal peptidases ( $s r t E$, $s r t F)$, several transporters, two-component systems and several other genes (Table 3).
Clustering of RD distribution among isolates in a dendrogram resulted in an identical clustering compared to CGH clustering, indicating that RDs mainly determine the differences between isolates as detected by CGH (Figure 3). Within cluster A, subclusters could not be discriminated based on the absence/presence of specific RDs, since most RDs were universally present within cluster A isolates. Distribution of RDs among cluster B was more heterogeneous. Three isolates from cluster B3 $\left(22083^{\mathrm{R} 1}, 8186\right.$ and OV640) were responsible for a good deal of diversity: 9 RDs representing 45 genes were only absent in one or more of these isolates; whereas in total at least 29 RDs are missing from these isolates. Thus, these isolates are atypical within our selection of isolates. Serotype 7 and 9 isolates (in clusters B2 and B5) also lacked considerable numbers of RDs. For some RDs (RD1, RD6, RD17), GC content differed considerably from overall GC content of the genome (41\%), indicating these RDs might have been acquired from other species by horizontal gene transfer, since foreign DNA can often be recognized by its variation from the majority of the genome in base composition or codon preference. The gene content of RDs shows that these regions contain specific beneficial traits like RM systems, ABC transporters, or two-component systems, making it attractive regions to acquire.

A core genome for $S$. suis was defined by selecting genes that were present in all S. suis isolates tested. The resulting core genome of $S$. suis consisted of 1492 genes (76\%) out of 1960 genes present on our array. Of those 1492 genes, 26 genes represent pseudogenes in P1/7. Composition of the core genome of $S$. suis was studied using the classification in clusters of orthologous groups of proteins (COG). Figure 4 displays the relative representation of each COG category in both P1/7 as well as in the core genome. Most COG categories were equally represented in both genomes. However, COG categories J (translation, ribosomal structure and biogenesis), E (amino acid transport and metabolism) and F (nucleotide transport and metabolism) were found to be overrepresented in the core genome. In conclusion, all isolates in our study share 1492 genes. The overrepresentation of the structural gene categories J, E, and F suggest this core genome suffices for growth, division and survival, whereas additional, beneficial traits are mainly encoded by RDs.

\section{Discussion}

Comparative genome hybridization (CGH) was used to study genetic heterogeneity among a collection of $55 \mathrm{~S}$. suis isolates. S. suis isolates were assigned to two clusters (A and $\mathrm{B})$.

CGH data was compared with MLST and pulse field gel electrophoresis (PFGE) [6] and amplified fragment 
Table 3 Regions of difference (RDs) identified in relation to P1/7

\begin{tabular}{|c|c|c|c|c|c|}
\hline $\mathrm{RD}^{\#}$ & Range in $\mathrm{P} 1 / 7^{*}$ & $\begin{array}{l}\text { Size } \\
\text { (bp)* }\end{array}$ & $\begin{array}{l}\text { Present in } \\
\mathrm{n} / 55 \text { strains } \\
\text { (parts present } \\
\text { in } \mathrm{n} / 55 \text { ) }\end{array}$ & $\% \mathrm{GC}^{\$}$ & Predicted Function* \\
\hline$\overline{\mathrm{RD} 01}$ & SSU0101- SSU0111 & 7.537 & $23(49)$ & 34.1 & Integrase, replication initiation factor, hypothetical proteins \\
\hline RD02 & SSU0178 - SSU0182 & 5.501 & 47 & 40.8 & PTS ॥B, transketolase \\
\hline RD03 & SSU0198 - SSU0209 & 14.234 & $37(13)$ & 33.7 & PTS IIABC transporter, glucosamine-6-phosphate isomerase, pseudogene \\
\hline RD04 & SSU0300 - SSU0305 & 5.455 & $36(17)$ & 43.0 & Dehydrogenase, flavin oxidoreductase, transcription regulator lipase \\
\hline RD05 & SSU0346 - SSU0350 & 7.680 & 29 & 38.8 & merR, hypothetical proteins \\
\hline RD06 & SSU0413 - SSU0418 & 8.624 & $29(14)$ & 33.6 & Hypothetical proteins \\
\hline RD07 & SSU0423 - SSU0428 & 8.383 & $30(11)$ & 39.3 & Signal peptidase, srtF \\
\hline RD08 & SSU0449 - SSU0453 & 2.475 & 52 & 36.0 & Signal peptidase, srtE \\
\hline RD09 & SSU0519 - SSU0556 & 27.705 & $30(6)$ & 35.6 & cps-genes, transposases \\
\hline RD10 & SSU0592 - SSU0600 & 8.410 & 52 & 36.7 & Hypothetical proteins, D-alanine transport \\
\hline RD11 & SSU0640 - SSU0642 & 5.514 & 42 & 42.5 & Type III RM \\
\hline $\mathrm{RD} 12$ & SSU0651 - SSU0655 & 7.674 & $34(5)$ & 38.8 & Type I RM \\
\hline $\mathrm{RD} 13$ & SSU0661 - SSU0670 & 10.283 & 50 & 40.1 & $\begin{array}{c}\text { PTS IIABC, formate acetyltransferase, fructose-6-phaphate aldolase, glycerol } \\
\text { dehydrogenase }\end{array}$ \\
\hline RD14 & SSU0673 - SSU0679 & 8.872 & 45 & 42.1 & $\begin{array}{l}\text { Piryidine nucleotide-disulphide oxidoreductase, DNA-binding protein, glycerol kinase, } \\
\text { alpha-glycreophophate oxidase, glycerol uptake facilitator, dioxygenase }\end{array}$ \\
\hline $\mathrm{RD} 15$ & SSU0684 - SSU0693 & 7.868 & 35 & 38.6 & $\begin{array}{c}\text { Phosphatase, phosphomethylpyrimidine kinase, hydroxyethylthiazole kinase, thiamine- } \\
\text { phosphate pyrophosphorylase, uridine phosphorylase, cobalt transport protein, ABC } \\
\text { transporter }\end{array}$ \\
\hline RD16 & SSU0804 - SSU0815 & 11.036 & 20 & 30.6 & Plasmid replication protein, hypothetical proteins \\
\hline RD17 & SSU0833 - SSU0835 & 2.386 & 31 & 34.1 & Lantibiotic immunity \\
\hline RD18 & SSU0850 - SSU0852 & 2.345 & 50 & 40.9 & Pyridine nucleotide-disulphide oxidoreductase, hypothetical proteins \\
\hline RD19 & SSU0902 - SSU0904 & 2.169 & 52 & 36.4 & Hypothetical proteins \\
\hline RD20 & SSU0963 - SSU0968 & 2.769 & 54 & 43.2 & Acetyltransferase, transposases \\
\hline RD21 & SSU0998 - SSU1008 & 13.688 & 54 & 42.3 & $\begin{array}{c}\text { Glycosyl hydrolase, UDP-N-acetylglucosamine 1-carboxyvinyltransferase, 2-deoxy-D- } \\
\text { gluconate 3-dehydrogenase, mannonate dehydratase, urinate isomerase, 2-dehydro-3- } \\
\text { deoxy-6-phosphogalactonate aldolase, beta-glucuronidase, carbohydrate kinase, sugar } \\
\text { transporter }\end{array}$ \\
\hline RD22 & SSU1047 - SSU1066 & 17.452 & 52 & 40.1 & $\begin{array}{c}\text { Hyaluronidase, PTS IIABCD, aldolase, kinase, sugar-phosphate isomerase, gluconate 5- } \\
\text { dehydrogenase, transposase }\end{array}$ \\
\hline RD23 & SSU1169 - SSU1172 & 4.850 & $53(1)$ & 42.6 & ABC transporter \\
\hline RD24 & SSU1271 - SSU1274 & 6.695 & $36(1)$ & 35.8 & Type I RM \\
\hline RD25 & SSU1285 - SSU1287 & 805 & 43 & 41.7 & Hypothetical proteins \\
\hline RD26 & SSU1308 - SSU1310 & 4.130 & 52 & 36.7 & PTS $\| A B C$ \\
\hline RD27 & SSU1330 - SSU1347 & 10.041 & 28 & 37.1 & Phage proteins, hypothetical proteins \\
\hline RD28 & SSU1369 - SSU1374 & 7.733 & 53 & 38.8 & Sucrose phosphorylase, ABC transporter \\
\hline RD29 & SSU1402 - SSU1407 & 5.018 & $29(24)$ & 41.2 & Bacitracin export, transposase \\
\hline RD30 & SSU1470 - SSU1476 & 10.163 & 52 & 35.4 & Two-component regulatory system, serum opacity factor \\
\hline RD31 & SSU1588 - SSU1592 & 7.771 & 52 & 40.9 & Type I RM, integrase \\
\hline RD32 & SSU1702 - SSU1715 & 23.640 & 45 & 43.4 & $\begin{array}{l}\text { Two-component regulatory system, tranpsoase, glucosaminidase, hypothetical proteins, } \\
\text { alpha-1,2,-mannosidase, eno-beta-N-acetylglucusaminidase }\end{array}$ \\
\hline RD33 & SSU1722 - SSU1727 & 4.924 & 30 & 38.3 & Acetyltransferase, hypothetical proteins, PTS IBBC \\
\hline RD34 & SSU1763 - SSU1768 & 6.153 & 29 & 47.1 & $\begin{array}{c}\text { Nicotinamide mononucleotide transporter, transcriptional regulator, hypothetical } \\
\text { proteins }\end{array}$ \\
\hline RD35 & SSU1855 - SSU1862 & 8.479 & 52 & 39.9 & PTS IIABC, hypothetical proteins, beta-glucosidase, 6-phospho-beta-glucosidase \\
\hline RD36 & SSU1872 - SSU1875 & 1.918 & 36 & 35.4 & RevS, CAAX amino terminal protease \\
\hline RD37 & SSU1881 - SSU1890 & 13.184 & 36 & 38.5 & srtB, C, D \\
\hline RD38 & SSU1927 - SSU1931 & 8.444 & 44 & 41.6 & $\beta$-glucosidase, two-compent regulatory system \\
\hline RD39 & SSU1942 - SSU1944 & 461 & 42 & 40.5 & mutT/NUDIX hydrolase \\
\hline
\end{tabular}

\# Region of difference is defined as regions of at least 3 ORFs that are absent from at least 1/55 S. suis strains tested.

* Naming, size and function prediction is based on genome sequence of P1/7 [7]

\$ GC-percentage of $\mathrm{P} 1 / 7$ genome is $41 \%$ 


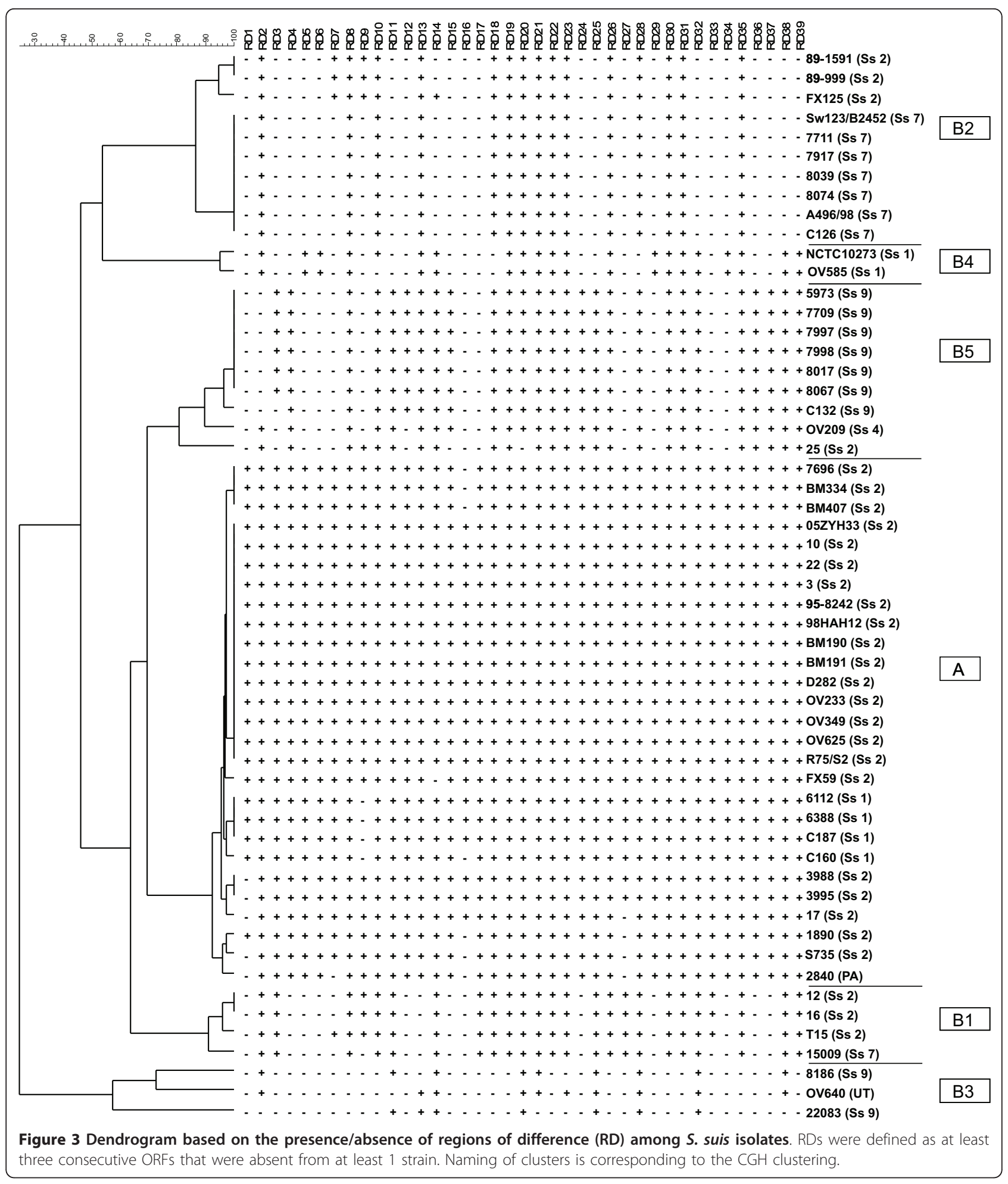

length polymorphism (AFLP)[25]. In general there was a lot of congruence between typing methods. The discriminatory power of $\mathrm{CGH}$ is larger than that of MLST analysis, since isolates that belong to MLST CC1 can be divided into subclusters using CGH. Moreover,
Vietnamese isolates that belong to different pulse field types, were assigned to the same CGH subcluster [6]. This could be explained by genomic inversions and substitutions, that were observed in the genome of the Vietnamese reference strain BM407 in comparison to P1/7 


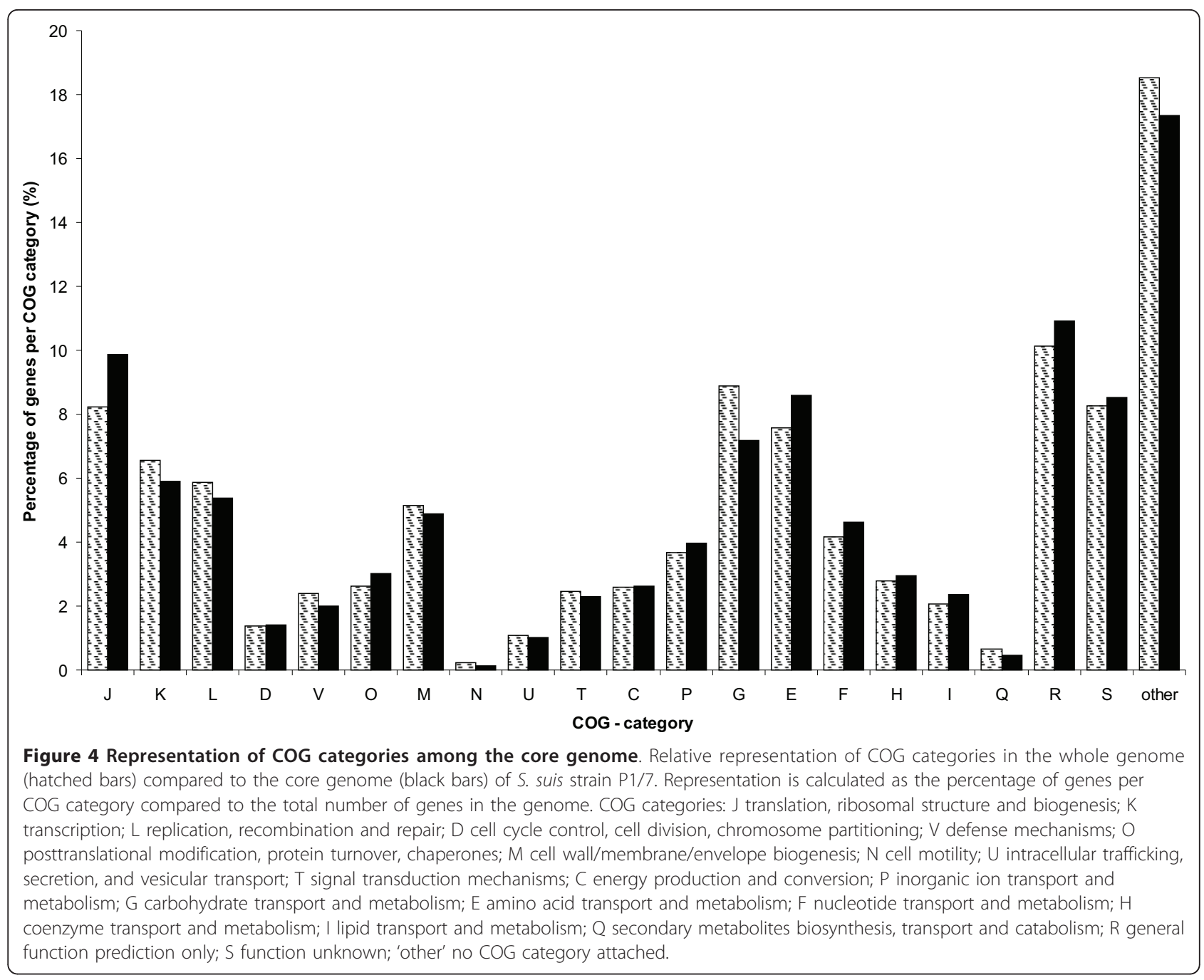

[7]. These changes can be discriminated by PFGE, but not by CGH.

To correlate virulence of isolates to CGH results, virulence of serotype 1 and serotype 9 isolates was determined in an experimental infection. For serotype 1, our animal experiment showed that in contrast to the field isolates, the reference strain was not highly virulent. Since serotype 9 only induced clinical symptoms at very high doses, we concluded that serotype 9 isolates were avirulent under experimental conditions. This was confirmed by other studies [32,33]. To correlate virulence to CGH data, distribution of 25 putative virulence genes among $S$. suis isolates was studied. Each CGH cluster was shown to be associated with a specific profile of putative virulence genes. Cluster A isolates contained all 25 putative virulence genes. Cluster B isolates on the contrary lacked up to 12 putative virulence genes among which one or more of sortase genes ( $\operatorname{srtBCD}$, $s r t E, \operatorname{srtF})$ that are involved in assembly of pili $[31,34]$.
In agreement with data presented here, Takamatsu et al. showed that CC1 isolates contained all srt genes, whereas CC29 isolates lacked $s r t B C D$ genes [34]. However, none of our serotype 9 isolates contained the $s r t B C D$ gene cluster, whereas this cluster was detected in a Japanese serotype 9 isolate [34]. This could imply geographical variation. Moreover, the revs gene is absent from all cluster B isolates, with the exception of cluster B5 isolates. This regulator influences expression of putative virulence factors [35]. Therefore, lack of revs might affect virulence of isolates. The IgA1 protease gene was found to be absent in all serotype 9 isolates, and displayed extensive sequence variation in serotype 7 isolates. All serotype 2 isolates including the avirulent isolates contained the IgA1 protease gene. Zhang et al. showed that most pathogenic serotype 2 isolates contained the IgA1 protease gene, whereas the gene was sparsely found in non-invasive serotype 2 isolates [36]. In the latter study mainly isolates obtained in China 
were used. Sequence variation among isolates belonging to cluster B was observed for other putative virulence genes as well, like ofs, $g \ln A, f b p s$ and $a p u A$. The ofs gene was highly conserved among virulent serotype 1 and 2 isolates but showed extensive sequence diversity in avirulent serotype 2 and serotype 7 isolates, as was also described by Takamatsu et al [15]. Interestingly, at least two of the ofs positive serotype 7 strains do not express OFS in vitro, as shown in the serum opacification assay [37]. This suggests the presence of silent ofs genes. A silent epf gene was present in isolates in cluster B3. Two of the B3 isolates $\left(22083^{\mathrm{R} 1}\right.$ and 8186$)$ expressed the enlarged version of MRP, but none of the probes used for the CGH hybridized to the mrp gene, suggesting extensive sequence variation exists between different serotype 9 isolates. The presence of a $m r p$ gene in the two isolates was confirmed by PCR analysis (data not shown). Serotype 9 isolates were distributed among 2 virulence clusters, V6 and V7 that differed considerably in their distribution of putative virulence genes. This suggests differences in virulence exist among serotype 9 isolates that were not identified in our experimental infection model.

Avirulent $\mathrm{MRP}^{-} \mathrm{EF}^{-}$serotype 2 isolates clustered together with serotype 7 isolates both by CGH as well as by MLST. Such a clustering is in agreement with previous studies $[24,25]$. The clustering strongly suggests similarity in genetic background between the isolates and could suggest that the avirulent serotype 2 isolates originated from serotype 7 isolates after the exchange of the capsular genes. Capsular exchange has been described for other streptococci like GBS [38] and Streptococcus pneumonia [39]. In this study 39 regions of differences (RDs) were identified, that might contribute to virulence or survival in the host based on the predicted functions of the genes associated with the various RDs. For example 3 RDs encode two-component regulatory systems and 5 RDs encode putative virulence genes. In addition, 6 phosphotransferase systems, and $4 \mathrm{ABC}$ transporters were identified. Since the GC content of some RDs differed considerably compared to the whole genome of $S$. suis, these RDs could have originated from horizontal gene transfer. This suggestion can be supported by the finding that many RDs contained transposases, integrases or phage proteins which are all involved in gene transfer.

A core genome for S. suis was defined that contained $78 \%$ of P1/7 ORFs. This percentage is in the same order of magnitude as for other streptococcal core genomes. A small percentage $(2.4 \%)$ of the core genome is represented by pseudogenes in P1/7. Since single nucleotide differences cannot be detected using CGH, additional putative pseudogenes present in other isolates will not be identified. This could lead to a small overestimation of the core genome. In P1/7 COG category G, carbohydrate transport and metabolism, is overrepresented compared to the core genome. This could reflect genes that are not essential to $S$. suis, but make $S$. suis strains carrying these gene(s) more versatile in their carbon source usage. Recent publications suggest carbon source usage may be an important virulence trait for streptococci [40], which implies the more versatile S. suis isolates could benefit in pathogenesis. Since the core genome includes genes that are shared by all isolates included in our study, representing virulent as well as avirulent isolates, it is not very likely the core genome alone is sufficient for virulence. This is confirmed by the finding of several genes putatively involved in virulence in the $\mathrm{RD}$ regions of $\mathrm{P} 1 / 7$ that probably attribute to virulence or survival in the host of P1/7. However, since all isolates, including avirulent ones like T15, 12 and 16 $[13,21]$, can colonize porcine tonsils, the core genome might be sufficient for colonization.

\section{Conclusions}

In conclusion, we show that $\mathrm{CGH}$ is a valuable method. Not only can it be used for genotyping of S. suis isolates, but CGH also gives information on phylogeny of isolates, and can be used to look for specific gene content, like virulence genes, or sequence variation among isolates. At present a disadvantage of $\mathrm{CGH}$ using the current microarray is the one way character of the technology; only distribution of genes present in P1/7 can be studied using the current microarray. Recently, several $S$. suis isolates have been sequenced adding new information to the $S$. suis pangenome. The Chinese human isolates were shown to contain an additional putative pathogenicity island (PI) of $89 \mathrm{~kb}$ compared to P1/7 [41], whereas the Vietnamese strain BM407 contained another additional PI compared to P1/7 [7]. Both PI's were shown to contain integrative and conjugative elements (ICE) not present in P1/7. The current microarray will have to be extended with genome sequences of other S. suis isolates to be a better representation of the $S$. suis pangenome.

\section{Acknowledgements}

We thank Albert de Boer for his assistance in visualizing data in dendrograms using BioNumerics. This project was financially supported by the Dutch Ministry of Agriculture, Nature and Food Quality (KB-08).

\section{Author details}

'Infection Biology, Central Veterinary Institute of Wageningen UR (University \& Research Centre), Edelhertweg 15, Lelystad, 8219 PH, The Netherlands. ${ }^{2}$ Centre for Poverty-Related Communicable Diseases, Academic Medical Centre, Meibergdreef 9, Amsterdam, The Netherlands. ${ }^{3}$ Oxford University Clinical Research Unit, Hospital for Tropical Diseases, 190 Ben Ham Tu, Ho Chi Minh City, Vietnam. ${ }^{4}$ Institut für Mikrobiologie, Zentrum für Infektionsmedizin, Stiftung Tierärtzliche Hochschule Hannover, Bünteweg 2, Hannover, Germany. 


\section{Authors' contributions}

AG carried out the molecular experiments, data analyses and drafted the manuscript. HJW collected the S. suis isolates and participated in the experimental infection. FMB performed statistical analysis of clustering methods. CS collected the Vietnamese isolates and helped to draft the manuscript. CGB collected and analyzed German isolates and helped to draft the manuscript. HNT analyzed the Vietnamese isolates. NSZ performed the experimental infections. HES initiated and coordinated the work described and helped to draft the manuscript. All authors read and approved the final manuscript.

\section{Conflicts of interests}

The authors declare that they have no competing interests.

Received: 6 December 2010 Accepted: 7 July 2011

Published: 7 July 2011

\section{References}

1. Arends JP, Hartwig N, Rudolphy M, Zanen HC: Carrier rate of Streptococcus suis capsular type 2 in palatine tonsils of slaughtered pigs. J Clin Microbiol 1984, 20(5):945-947.

2. Staats JJ, Feder I, Okwumabua O, Chengappa MM: Streptococcus suis: past and present. Vet Res Commun 1997, 21(6):381-407.

3. Ye C, Zhu X, Jing H, Du H, Segura M, Zheng H, Kan B, Wang L, Bai X, Zhou $Y$, et al: Streptococcus suis sequence type 7 outbreak, Sichuan, China. Emerg Infect Dis 2006, 12(8):1203-1208.

4. Tang J, Wang C, Feng Y, Yang W, Song H, Chen Z, Yu H, Pan X, Zhou X, Wang $H$, et al: Streptococcal toxic shock syndrome caused by Streptococcus suis serotype 2. PLoS medicine 2006, 3(5):e151.

5. Takamatsu D, Wongsawan $K$, Osaki M, Nishino H, Ishiji T, Tharavichitkul $P$, Khantawa B, Fongcom A, Takai S, Sekizaki T: Streptococcus suis in humans, Thailand. Emerg Infect Dis 2008, 14(1):181-183.

6. Mai NT, Hoa NT, Nga TV, Linh le D, Chau TT, Sinh DX, Phu NH, Chuong LV, Diep TS, Campbell J, et al: Streptococcus suis meningitis in adults in Vietnam. Clin Infect Dis 2008, 46(5):659-667.

7. Holden MT, Hauser H, Sanders M, Ngo TH, Cherevach I, Cronin A, Goodhead I, Mungall K, Quail MA, Price C, et al: Rapid evolution of virulence and drug resistance in the emerging zoonotic pathogen Streptococcus suis. PLoS One 2009, 4(7):e6072.

8. Hill JE, Gottschalk M, Brousseau R, Harel J, Hemmingsen SM, Goh SH: Biochemical analysis, cpn60 and 16S rDNA sequence data indicate that Streptococcus suis serotypes 32 and 34, isolated from pigs, are Streptococcus orisratti. Vet Microbiol 2005, 107(1-2):63-69.

9. Wisselink HJ, Smith HE, Stockhofe-Zurwieden N, Peperkamp K, Vecht U: Distribution of capsular types and production of muramidase-released protein (MRP) and extracellular factor (EF) of Streptococcus suis strains isolated from diseased pigs in seven European countries. Vet Microbiol 2000, 74(3):237-248.

10. Fittipaldi N, Fuller TE, Teel JF, Wilson TL, Wolfram TJ, Lowery DE, Gottschalk M: Serotype distribution and production of muramidasereleased protein, extracellular factor and suilysin by field strains of Streptococcus suis isolated in the United States. Vet Microbiol 2009.

11. Messier S, Lacouture S, Gottschalk M: Distribution of Streptococcus suis capsular types from 2001 to 2007. Can Vet J 2008, 49(5):461-462.

12. Vela Al, Goyache J, Tarradas C, Luque I, Mateos A, Moreno MA, Borge C, Perea JA, Dominguez L, Fernandez-Garayzabal JF: Analysis of genetic diversity of Streptococcus suis clinical isolates from pigs in Spain by pulsed-field gel electrophoresis. J Clin Microbiol 2003, 41(6):2498-2502.

13. Vecht U, Wisselink HJ, Jellema ML, Smith HE: Identification of two proteins associated with virulence of Streptococcus suis type 2. Infect Immun 1991, 59(9):3156-3162

14. Gottschalk M, Segura M, Xu J: Streptococcus suis infections in humans: the Chinese experience and the situation in North America. Anim Health Res Rev 2007, 8(1):29-45

15. Takamatsu D, Osaki M, Tharavichitkul P, Takai S, Sekizaki T: Allelic variation and prevalence of serum opacity factor among the Streptococcus suis population. J Med Microbiol 2008, 57:(Pt 4):488-494.

16. Smith $H E$, Reek FH, Vecht $U$, Gielkens AL, Smits MA: Repeats in an extracellular protein of weakly pathogenic strains of Streptococcus suis type 2 are absent in pathogenic strains. Infect Immun 1993, 61(8):3318-3326.
17. King SJ, Allen AG, Maskell DJ, Dowson CG, Whatmore AM: Distribution, genetic diversity, and variable expression of the gene encoding hyaluronate lyase within the Streptococcus suis population. J Bacteriol 2004, 186(14):4740-4747.

18. Vecht U, van Leengoed LA, Verheijen ER: Streptococcus suis infections in pigs in the Netherlands (Part I). The Veterinary quarterly 1985, 7(4):315-321.

19. Smith HE, Wisselink HJ, Stockhofe-Zurwieden N, Vecht U, Smits MM: Virulence markers of Streptococcus suis type 1 and 2. Adv Exp Med Biol 1997, 418:651-655.

20. Jacobs AA, Loeffen PL, van den Berg AJ, Storm PK: Identification, purification, and characterization of a thiol-activated hemolysin (suilysin) of Streptococcus suis. Infect Immun 1994, 62(5):1742-1748.

21. Vecht U, Wisselink HJ, van Dijk JE, Smith HE: Virulence of Streptococcus suis type 2 strains in newborn germfree pigs depends on phenotype. Infect Immun 1992, 60(2):550-556.

22. Segers RP, Kenter T, de Haan LA, Jacobs AA: Characterisation of the gene encoding suilysin from Streptococcus suis and expression in field strains. FEMS Microbiol Lett 1998, 167(2):255-261.

23. Vecht U, Arends JP, van der Molen EJ, van Leengoed LA: Differences in virulence between two strains of Streptococcus suis type II after experimentally induced infection of newborn germ-free pigs. Am J Vet Res 1989, 50(7):1037-1043.

24. King SJ, Leigh JA, Heath PJ, Luque I, Tarradas C, Dowson CG, Whatmore AM: Development of a multilocus sequence typing scheme for the pig pathogen Streptococcus suis: identification of virulent clones and potential capsular serotype exchange. J Clin Microbiol 2002, 40(10):3671-3680

25. Rehm T, Baums CG, Strommenger B, Beyerbach M, Valentin-Weigand $P$, Goethe R: Amplified fragment length polymorphism of Streptococcus suis strains correlates with their profile of virulence-associated genes and clinical background. J Med Microbiol 2007, 56(Pt 1):102-109.

26. De Greeff A, Buys H, Verhaar R, Van Alphen L, Smith HE: Distribution of environmentally regulated genes of Streptococcus suis serotype 2 among S. suis serotypes and other organisms. J Clin Microbiol 2002, 40(9):3261-3268.

27. Feil EJ, Li BC, Aanensen DM, Hanage WP, Spratt BG: eBURST: inferring patterns of evolutionary descent among clusters of related bacterial genotypes from multilocus sequence typing data. J Bacteriol 2004, 186(5):1518-1530.

28. Saulnier DM, Molenaar D, de Vos WM, Gibson GR, Kolida S: Identification of prebiotic fructooligosaccharide metabolism in Lactobacillus plantarum WCFS1 through microarrays. Appl Environ Microbiol 2007, 73(6):1753-1765.

29. Molenaar D, Bringel F, Schuren FH, de Vos WM, Siezen RJ, Kleerebezem M. Exploring Lactobacillus plantarum genome diversity by using microarrays. J Bacteriol 2005, 187(17):6119-6127.

30. van Hijum SA, Baerends RJ, Zomer AL, Karsens HA, Martin-Requena V, Trelles O, Kok J, Kuipers OP: Supervised Lowess normalization of comparative genome hybridization data-application to lactococcal strain comparisons. BMC bioinformatics 2008, 9:93.

31. Fittipaldi N, Takamatsu D, de la Cruz Dominguez-Punaro M, Lecours MP Montpetit D, Osaki M, Sekizaki T, Gottschalk M: Mutations in the gene encoding the ancillary pilin subunit of the Streptococcus suis srtF cluster result in pili formed by the major subunit only. PLoS One 5(1):e8426.

32. Stockhofe-Zurwieden $\mathrm{N}$, Vecht U, Wisselink HJ, van Lieshout $\mathrm{H}$, Smith HE: Comparative studies on the pathogenicity of different Streptococcus suis type 1 strains. 14th IPVS: 1996 1996; Bologna 1996, 299.

33. Beineke A, Bennecke K, Neis C, Schroder C, Waldmann KH, Baumgartner W, Valentin-Weigand P, Baums CG: Comparative evaluation of virulence and pathology of Streptococcus suis serotypes 2 and 9 in experimentally infected growers. Vet Microbiol 2008, 128(3-4):423-430.

34. Takamatsu D, Nishino H, Ishiji T, Ishii J, Osaki M, Fittipaldi N, Gottschalk M, Tharavichitkul P, Takai S, Sekizaki T: Genetic organization and preferential distribution of putative pilus gene clusters in Streptococcus suis. Vet Microbiol 2009, 138(1-2):132-139.

35. Wu T, Chang H, Tan C, Bei W, Chen H: The orphan response regulator RevSC21 controls the attachment of Streptococcus suis serotype-2 to human laryngeal epithelial cells and the expression of virulence genes. FEMS Microbiol Lett 2009, 292(2):170-181.

36. Zhang A, Mu X, Chen B, Liu C, Han L, Chen H, Jin M: Identification and characterization of $\lg A 1$ protease from Streptococcus suis. Vet Microbiol 140(1-2):171-175. 
37. Baums CG, Kaim U, Fulde M, Ramachandran G, Goethe R, ValentinWeigand P: Identification of a novel virulence determinant with serum opacification activity in Streptococcus suis. Infect Immun 2006, 74(11):6154-6162.

38. Cieslewicz MJ, Chaffin D, Glusman G, Kasper D, Madan A, Rodrigues S, Fahey J, Wessels MR, Rubens CE: Structural and genetic diversity of group B streptococcus capsular polysaccharides. Infect Immun 2005, 73(5):3096-3103

39. Coffey TJ, Dowson CG, Daniels M, Spratt BG: Horizontal spread of an altered penicillin-binding protein $2 \mathrm{~B}$ gene between Streptococcus pneumoniae and Streptococcus oralis. FEMS Microbio/ Lett 1993, 110(3):335-339.

40. Sitkiewicz I, Green NM, Guo N, Bongiovanni AM, Witkin SS, Musser JM: Adaptation of group a streptococcus to human amniotic fluid. PLoS One 5(3):e9785.

41. Chen C, Tang J, Dong W, Wang C, Feng Y, Wang J, Zheng F, Pan X, Liu D, $L i M$, et al: A glimpse of streptococcal toxic shock syndrome from comparative genomics of S. suis 2 Chinese isolates. PLOS ONE 2007, 2(3): e315.

42. Li Y, Martinez G, Gottschalk M, Lacouture S, Willson P, Dubreuil JD, Jacques M, Harel J: Identification of a surface protein of Streptococcus suis and evaluation of its immunogenic and protective capacity in pigs. Infect Immun 2006, 74(1):305-312.

43. Allen AG, Lindsay $H$, Seilly D, Bolitho S, Peters SE, Maskell DJ: Identification and characterisation of hyaluronate lyase from Streptococcus suis. Microb Pathog 2004, 36(6):327-335.

44. de Greeff A, Buys H, Verhaar R, Dijkstra J, van Alphen L, Smith HE: Contribution of fibronectin-binding protein to pathogenesis of Streptococcus suis serotype 2. Infect Immun 2002, 70(3):1319-1325.

45. Winterhoff N, Goethe R, Gruening P, Rohde M, Kalisz H, Smith HE, ValentinWeigand $P$ : Identification and characterization of two temperatureinduced surface-associated proteins of Streptococcus suis with high homologies to members of the Arginine Deiminase system of Streptococcus pyogenes. J Bacteriol 2002, 184(24):6768-6776.

46. Brassard J, Gottschalk M, Quessy S: Cloning and purification of the Streptococcus suis serotype 2 glyceraldehyde-3-phosphate dehydrogenase and its involvement as an adhesin. Vet Microbiol 2004, 102(1-2):87-94.

47. de Greeff A, Buys $H$, van Alphen L, Smith HE: Response regulator important in pathogenesis of Streptococcus suis serotype 2. Microb Pathog 2002, 33(4):185-192.

48. Esgleas M, Dominguez-Punaro Mde L, Li Y, Harel J, Dubreuil JD, Gottschalk M: Immunization with SsEno fails to protect mice against challenge with Streptococcus suis serotype 2. FEMS Microbiol Lett 2009, 294(1):82-88.

49. Si Y, Yuan F, Chang H, Liu X, Li H, Cai K, Xu Z, Huang Q, Bei W, Chen H: Contribution of glutamine synthetase to the virulence of Streptococcus suis serotype 2. Vet Microbiol 2009, 139(1-2):80-88.

50. Zhang XH, He KW, Duan ZT, Zhou JM, Yu ZY, Ni YX, Lu CP: Identification and characterization of inosine 5-monophosphate dehydrogenase in Streptococcus suis type 2. Microb Pathog 2009, 47(5):267-273.

51. Ge J, Feng Y, Ji H, Zhang H, Zheng F, Wang C, Yin Z, Pan X, Tang J: Inactivation of dipeptidyl peptidase IV attenuates the virulence of Streptococcus suis serotype 2 that causes streptococcal toxic shock syndrome. Current microbiology 2009, 59(3):248-255.

52. Aranda J, Cortes P, Garrido ME, Fittipaldi N, Llagostera M, Gottschalk M, Barbe J: Contribution of the FeoB transporter to Streptococcus suis virulence. Int Microbiol 2009, 12(2):137-143.

53. Hu Q, Liu P, Yu Z, Zhao G, Li J, Teng L, Zhou M, Bei W, Chen H, Jin M: Identification of a cell wall-associated subtilisin-like serine protease involved in the pathogenesis of Streptococcus suis serotype 2. Microb Pathog 2009.

54. Ferrando LM, Fuentes $S$, de Greeff A, Smith $H$, Wells JM: ApuA a Multifunctional \{alpha\}-Glucan-degrading Enzyme of Streptococcus suis Mediates Adhesion to Porcine Epithelium and Mucus. Microbiology .

55. Aranda J, Garrido ME, Fittipaldi N, Cortes P, Llagostera M, Gottschalk M, Barbe J: The cation-uptake regulators AdcR and Fur are necessary for full virulence of Streptococcus suis. Vet Microbiol 144(1-2):246-249.

56. Quessy S, Dubreuil JD, Caya M, Higgins R: Discrimination of virulent and avirulent Streptococcus suis capsular type 2 isolates from different geographical origins. Infect Immun 1995, 63(5):1975-1979. doi:10.1186/1471-2180-11-161

Cite this article as: de Greeff et al:: Genetic diversity of Streptococcus suis isolates as determined by comparative genome hybridization. BMC Microbiology 2011 11:161.

\section{Submit your next manuscript to BioMed Central and take full advantage of:}

- Convenient online submission

- Thorough peer review

- No space constraints or color figure charges

- Immediate publication on acceptance

- Inclusion in PubMed, CAS, Scopus and Google Scholar

- Research which is freely available for redistribution 